\title{
Promoter mutation of tumor suppressor microRNA-7 is associated with poor prognosis of lung cancer
}

\author{
JUANJUAN ZHAO $^{1 *}$, KAILING WANG $^{2 *}$, ZHENYUAN LIAO $^{1 *}$, YING LI $^{1}$, HANG YANG $^{2}$,

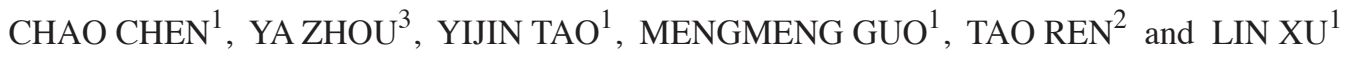 \\ ${ }^{1}$ Department of Immunology, Zunyi Medical College, Zunyi, Guizhou 563000; \\ ${ }^{2}$ Department of Respiratory Medicine, East Hospital, Tongji University, Shanghai 200120; \\ ${ }^{3}$ Department of Medical Physics, Zunyi Medical College, Zunyi, Guizhou 563000, P.R. China
}

Received March 9, 2015; Accepted August 28, 2015

DOI: $10.3892 / \mathrm{mco} .2015 .648$

\begin{abstract}
The significance of promoter mutations of microRNAs (miRNAs) in lung cancer is poorly understood. Recent evidence demonstrated that miRNA-7 (miR-7), a unique member of the miRNA family, exhibited decreased expression and has emerged as an important regulator in lung tumorigenesis. However, the mechanism underlying the downregulation of miR-7 in lung cancer remains largely unknown. In this study, we investigated the sites of mutation of the miR-7 promoter in lung cancer tissues using DNA sequencing. We identified a $\mathrm{G} \rightarrow \mathrm{C}$ change at the -617 site $(25 / 39,64.1 \%)$ and an $\mathrm{A} \rightarrow \mathrm{G}$ change at the -604 site $(20 / 39,51.3 \%)$ in the miR-7 promoter region in lung cancer tissues. Moreover, the expression of miR-7 in cancer tissue with promoter site mutations was lower compared with that in cancer tissue without mutations $(\mathrm{P}<0.05)$. Furthermore, we demonstrated that mutations at these sites may decrease the activity of the miR-7 promoter and alter the expression of miR-7. Notably, mutations at these sites of the miR-7 promoter were found to be closely associated with poor prognosis of lung cancer patients $(\mathrm{P}=0.037)$. These data may provide novel insight on the altered expression
\end{abstract}

Correspondence to: $\mathrm{Dr}$ Lin $\mathrm{Xu}$, Department of Immunology, Zunyi Medical College, 201 Dalian Road, Zunyi, Guizhou 563000, P.R. China

E-mail: xulinzhouya@163.com

Dr Tao Ren, Department of Respiratory Medicine, East Hospital, Tongji University, 150 Jimo Road, Pudong New Area, Shanghai 200120, P.R. China

E-mail:rentao305@163.com

*Contributed equally

Abbreviations: miRNA, microRNA; miR-7, miRNA-7; HuR, human $\mathrm{R}$ antigen; Mu, mutation; WT, wild-type

Key words: promoter mutation, microRNA-7, lung cancer, prognosis of specific miRNA molecules in lung cancer and ultimately prove to be helpful in the development of prognostic and therapeutic strategies against lung cancer.

\section{Introduction}

Lung cancer is one of the most common causes of cancer-related mortality. To date, multiple genes have been found to exhibit altered expression in the pathogenesis of lung cancer $(1,2)$. Furthermore, the altered expression of these genes was found to be closely associated with the mutation or methylation of promoter sites of these genes $(3,4)$. The overall 5-year survival rate of lung cancer patients receiving traditional treatment remains poor (5). Thus, it is crucial to identify and characterize novel molecular markers and gene targets, as well as investigate the mechanism underlying their altered expression, in order to improve the accuracy of prognosis and develop optimal targeted treatment strategies to improve the clinical outcome of lung cancer patients.

Recently, a growing body of literature has demonstrated that microRNAs (miRNAs), a class of non-coding RNA molecules that regulate the expression of protein-coding genes through binding to the 3'-untranslated regions of target mRNAs, have emerged as important regulators in the development of lung cancer and a novel potential target for the development of therapeutic strategies for lung cancer patients $(6,7)$. Various specific miRNA molecules were reported to exhibit repressed expression in lung cancer tissues and to be closely associated with patient prognosis $(8,9)$. However, the mechanism underlying the altered expression of these specific miRNA molecules in lung cancer, including mutation or methylation of their promoter regions, remains largely unknown.

miRNA (miR)-7, a distinct member of the miRNA family, was reported to be able to regulate the biology of various tumor cells through repressing the expression of different target molecules (10-13). miR-7 expression was found to be repressed in lung cancer tissues $(7,14)$. Moreover, miR-7 was able to suppress the growth and metastatic potential of human lung cancer cells in vitro (15). Our previous studies also demonstrated that overexpression of miR-7 reduced the growth and metastasis of human lung cancer cells in vivo $(16,17)$. These findings suggested that miR-7, as a tumor suppressor, may be 
a potential candidate as a prognostic marker and a therapeutic target in lung cancer. However, the presence of mutations in the miR-7 promoter and their possible association with the prognosis of lung cancer remain to be elucidated.

The aim of this study was to investigate the presence of promoter mutations of miR-7 in lung cancer and their possible association with the prognosis of the patients.

\section{Patients and methods}

Patients and tissue samples. A total of 39 Chinese patients who were diagnosed with lung cancer between 2007 and 2008 were included in the present study. Clinical and pathological information, including age, gender, smoking status, type of tumor and disease stage, were collected. Paraffin blocks and fresh-frozen tumor specimens of tumor samples from all 39 patients were prepared. In addition, 8 samples from normal tissues adjacent to the tumors were also collected. All the patients were followed up until December, 2012. This study was approved by the Ethics Committee of the First Hospital of Zunyi Medical College (Guizhou, China) and written informed consent was obtained from all the participants.

Sample preparation. Tissue sections $(4-5 \mu \mathrm{m})$ were cut from the paraffin blocks for pathological analysis. Total RNA was extracted from the fresh-frozen tumor specimens for the detection of miR-7 expression in lung cancer or normal lung tissues. Genomic DNA was isolated from the frozen specimens using a NucleoSpin Tissue kit (Clontech Laboratories Inc., Mountain View, CA, USA) according to the manufacturer's instructions. The DNA samples were frozen at $-70^{\circ} \mathrm{C}$ until use.

Amplification of the 5'-flanking region of the human miR-7 gene by polymerase chain reaction (PCR) analysis. PCR primer sets were designed to amplify a $1.3-\mathrm{kb}$ product containing -1068 and +234 sites from the 5 -flanking region of the human miR-7-2 gene. The sequences of the primer sets were as follows: Sense (-1068 to -1051): 5'-AGCACCAATAGG GAAGGG-3'; and antisense (+217 to +234): 5'-GAGTCTGCC GATGGGTGT-3'. PCR was performed in $50 \mu 1$ of reaction mixture containing $20 \mathrm{mmol} / \mathrm{l}$ Tris- $\mathrm{HCl}, \mathrm{pH} 8.8$, $2 \mathrm{mmol} / 1 \mathrm{MgSO}_{4}, 10 \mathrm{mmol} / 1 \mathrm{KCl}, 10 \mathrm{mmol} / 1\left(\mathrm{NH}_{4}\right)_{2} \mathrm{SO}_{4}$, $0.1 \%$ Triton $\mathrm{X}-100,1 \mathrm{mg} / \mathrm{ml}$ nuclease-free bovine serum albumin, $10 \mathrm{mmol} / \mathrm{l}$ each of dATP, dCTP, dGTP and dTTP, $0.2 \mathrm{pM}$ of each primer, $6 \%$ dimethyl sulfoxide, $1 \mu \mathrm{g}$ genomic DNA and 2.5 U Pyrococcus furiosus DNA polymerase. The thermal cycling settings for PCR included a 5-min initial denaturation at $95^{\circ} \mathrm{C}$ followed by 35 amplification cycles (denaturation for $1 \mathrm{~min}$ at $94^{\circ} \mathrm{C}$, annealing for $1 \mathrm{~min}$ at $58^{\circ} \mathrm{C}$ and extension for $1.5 \mathrm{~min}$ at $72^{\circ} \mathrm{C}$, with a final extension step at $72^{\circ} \mathrm{C}$ for $\left.10 \mathrm{~min}\right)$. The PCR products were analyzed on a $1 \%$ agarose gel in Tris-acetate buffer with ethidium bromide staining. The PCR products were then purified from the agarose gels using the GeneClean kit (Bio101 Inc., Vista, CA, USA) according to the manufacturer's recommendations.

Sequence analysis. To investigate mutations in the promoter region of the human miR-7 gene, the above products of PCR templates were prepared and the nucleotide sequence was determined on both strands by Sanger's dideoxynucleotide chain-termination method with Sequenase 2.0 (Amersham Pharmacia Biotech, Piscataway, NJ, USA). Multiple overlapping fragments were sequenced at least twice in each direction and the DNA sequence was analyzed using MacVector software (Eastman Kodak Co., Rochester, NY, USA). DNA sequence analysis was performed by a manual method (Thermo Sequenase Cycle Sequencing kit; Amersham Pharmacia Biotech) and an automatic sequence method (Applied Biosystems, Foster City, CA, USA) according to the manufacturer's instructions.

Construction of the eukaryotic vector. PCR primer sets were designed to amplify a $1.3-\mathrm{kb}$ product containing -1068 and +234 sites from the 5'-flanking region of the human miR-7-2 gene. The sequences of the primer sets were as follows: Sense (-1068 to -1051): 5'-CTAGCTAGCTAGAGCACCAATAGG GAAGGG-3'; and antisense (+217 to +234): 5'-GAAGATCTT CGAGTCTGCCGATGGGTGT-3'. The PCR products were amplified from DNA derived from lung cancer tissues with or without miR-7 promoter mutations, then subcloned into NheI and $B g l$ II sites of the pGL3.0 basic vector (Invitrogen Corporation, San Diego, CA, USA) to generate the pGL3.0-miR-7 expression plasmid [referred to as p-wild-type (WT)-miR-7 or p-mutation (Mu)-miR-7, respectively]. For the construction of plasmids pGL-miR-7 promoter Luc, the promoter region (-1068 to $0 \mathrm{bp}$ ) of $\mathrm{miR}-7$ was amplified from DNA derived from lung cancer tissues with or without miR-7 promoter mutations using a forward primer (5'-CTAGCTAGC TAGAGCACCAATAGGGAAGGG) and a reverse primer (5'-GAAGATCTTCGCCAGTTCTGCAAGGCGT) and subcloned into NheI and $B g l$ II sites of the pGL basic vector (referred to as p-WT-promoter or p-Mu-promoter, respectively). Clone identity was verified using restriction digest analysis and plasmid DNA sequencing. Endotoxin-free plasmids were obtained using the EndoFree Plasmid Mega kit (Qiagen, Hilden, Germany). The plasmids were then transiently transferred into the 95D human lung cancer cells using Lipofectamine ${ }^{\circledR}-2000$ (Invitrogen Corporation) in the following experiments according to the manufacturer's instructions.

Luciferase reporter assay. The 95D cells were transiently co-transfected with the $\mathrm{p}$-WT-promoter or $\mathrm{p}-\mathrm{Mu}$-promoter and pCMV-lacZ plasmids using Lipofectamine-2000 (Invitrogen Corporation) according to the manufacturer's instructions and cultured in $37^{\circ} \mathrm{C}$. After $24 \mathrm{~h}$, luciferase and $\beta$-galactosidase ( $\beta$-gal) activity in $100 \mu \mathrm{l}$ of cell lysate were measured using the Luciferase Assay system and the $\beta$-Galactosidase Enzyme Assay system (Promega Corporation, Madison, WI, USA), respectively. Transfection efficiency was normalized using $\beta$-gal activity.

Quantitative PCR ( $q P C R$ ) assay. All the reagents, primers and probes were obtained from Applied Biosystems. The relative expression of miR-7 was determined as previously described (17). Briefly, a $\beta$-actin endogenous control was used for normalization. Reverse transcription (RT) reactions and qPCR were performed according to the manufacturer's protocols (Applied Biosystems). RNA concentrations were determined with a NanoDrop instrument (NanoDrop 
A

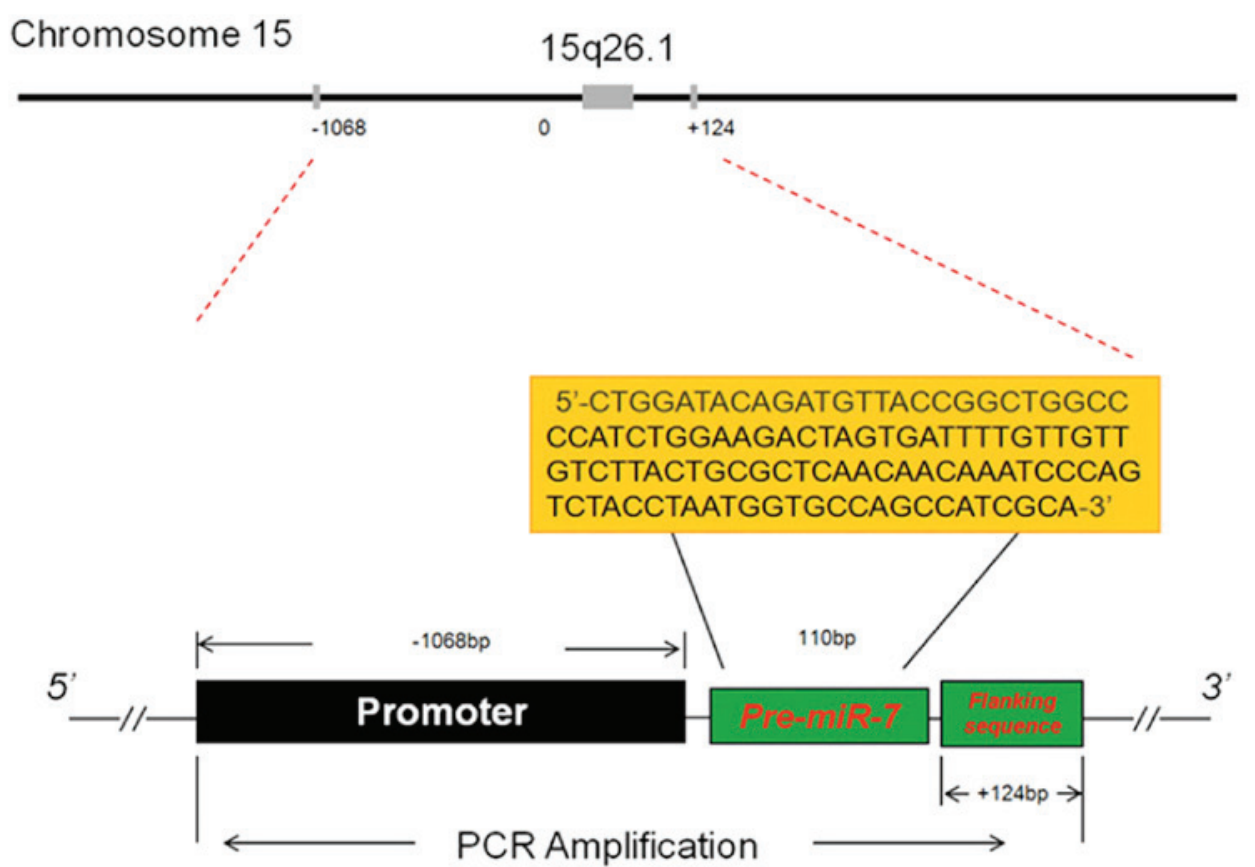

(Product:1302bp)

B

\section{Normal}

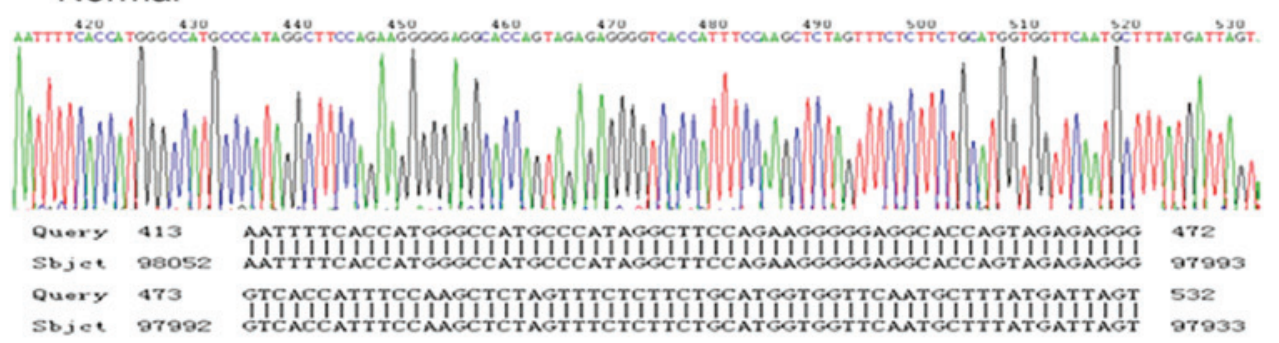

\section{Cancer}

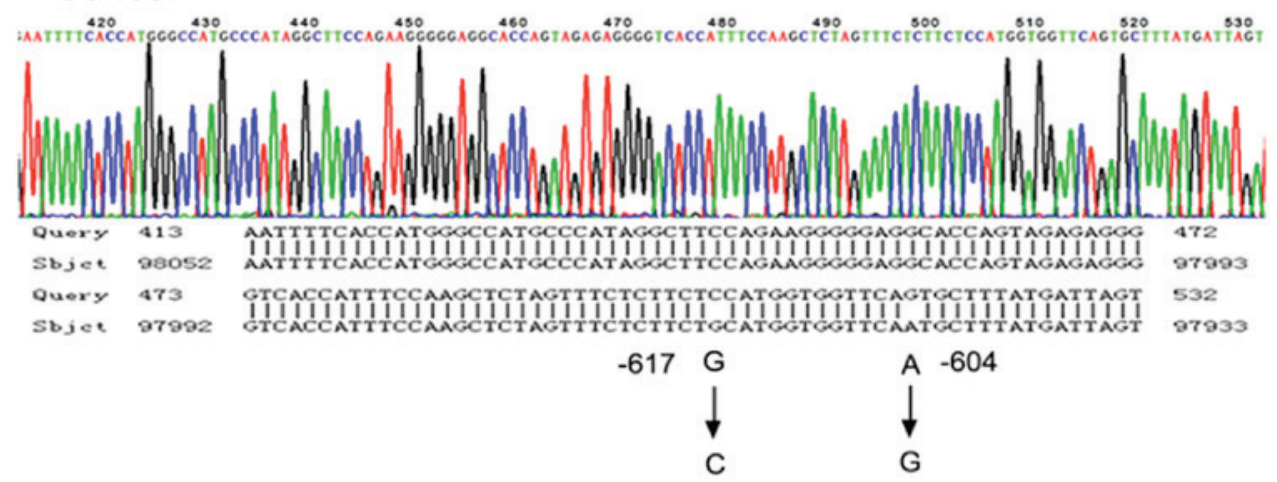

Figure 1. MicroRNA-7 (miR-7) promoter mutation in lung cancer. (A) Schematic representation of the human miR-7 gene and sequencing strategy for the 5'-flanking region of the gene. The coding sequences are depicted in the yellow box. The fragment containing the 5'-flanking region and 234 bp downstream from the initial site of the human pre-miR-7 gene was amplified by polymerase chain reaction (PCR) from lung cancer or normal lung tissues. (B) DNA sequence analysis of the PCR products from lung cancer or normal lung tissues. The wild-type sequence were isolated from normal lung tissues. Mutations in lung cancer tissues are identified at the indicated positions. $\mathrm{G} \rightarrow \mathrm{C}$ at -617 and $\mathrm{A} \rightarrow \mathrm{G}$ at -604 .

Technologies, Wilmington, DE, USA). One nanogram of RNA per sample was used for the assays. All RT reactions, including no-template controls and RT minus controls, were run in triplicate in GeneAmp ${ }^{\circledR}$ PCR 9700 thermal cycler
(Applied Biosystems). The gene expression levels were quantified using the ABI PRISM ${ }^{\circledR} 7900$ HT Sequence Detection system (Applied Biosystems). Relative expression was calculated using the comparative threshold cycle method. 
Cell proliferation assays. 95D cells transiently transfected with $10 \mathrm{nmol}$ p-WT-miR-7 or p-Mu-miR-7 vector using Lipofectamine-2000 (Invitrogen Corporation) were seeded at $3 \times 10^{3}$ cells per well and incubated at $37^{\circ} \mathrm{C}$ in $5 \% \mathrm{CO}_{2}$ in 96-well plates for $72 \mathrm{~h}$. Cell proliferation was measured in terms of optical absorbance per well by a semi-automated tetrazolium-based colorimetric assay using MTT.

Statistical analysis. Statistical evaluation was performed using one-way analysis of variance $(\mathrm{P}<0.05)$. All comparisons between categorical variables were performed by the Fisher's exact Chi-square test. Relapse-free survival was calculated using the Kaplan-Meier survival estimates and the log-rank test from the date of diagnosis until the last contact or relapse. $\mathrm{P}<0.05$ was considered to indicate a statistically significant difference. Statistical analyses were conducted using SPSS 13.0 software for Windows (SPSS, Inc., Chicago, IL, USA).

\section{Results}

Promoter mutation of miR-7 in lung cancer. To elucidate the mechanism underlying the reduced expression of human miR-7 in lung cancer, we first searched for the putative promoter region in the 5'-flanking region, which may alter miR-7 gene transcription according to a previous report (13). Sequence analysis revealed putative transcription factor binding sites for SRY, c-Myc, Gfi-1 and CdxA in the 5'-flanking region, suggesting that the expression of the human miR-7 gene may be controlled by these regulatory elements (data not shown). Primer sets were used to amplify overlapping fragments from the 5'-flanking region from -1068 bp upstream to $+234 \mathrm{bp}$ downstream from the initiation site of pre-miR-7 (Fig. 1A) from the genomic DNA. The sizes of PCR products amplified from the genomic DNA of lung cancer and normal lung tissues were identical and corresponded to the expected sizes, indicating that there were no major additions or deletions in the 5'-flanking region of the human miR-7 gene in the lung cancer tissues examined. Subsequently, the PCR products were sequenced to assess the promoter mutation of miR-7 of lung cancer tissues from 39 lung cancer patients and normal lung tissues from 8 healthy donors, respectively. Detailed DNA sequence analysis identified two mutations in the PCR region in lung cancer tissues, namely a $\mathrm{G} \rightarrow \mathrm{C}$ change at -617 and a $\mathrm{A} \rightarrow \mathrm{G}$ change at -604 (Fig. 1B). Moreover, as shown in Table I, the promoter mutation at the -617 site of miR-7 was detected in 25 patients $(64.1 \%)$ and at the -604 site in 20 patients (51.3\%). All $\mathrm{A} \rightarrow \mathrm{G}$ mutations were found in combination with the $\mathrm{G} \rightarrow \mathrm{C}$ mutation; the $\mathrm{A} \rightarrow \mathrm{G}$ mutation alone was not detected in any patients $(0 \%)$, whereas the $\mathrm{G} \rightarrow \mathrm{C}$ mutation alone was detected in 5 patients (12.8\%). However, promoter mutations were not detected in normal lung tissues $(0 \%)$. We then investigated the association between mutation sites of the miR-7 promoter and a significant correlation was observed between the $\mathrm{G} \rightarrow \mathrm{C}$ and $\mathrm{A} \rightarrow \mathrm{G}$ sites $(\mathrm{P}<0.05)$.

The mutation sites alter the activity of the miR-7 promoter. To determine whether the mutations affected the activity of the miR-7 promoter, PCR-amplified promoter fragments (-1068 to 0$)$, with or without the two mutations, were obtained
Table I. Mutation in the promoter region of the human microRNA-7 gene in lung cancer $(\mathrm{n}=39)$.

\begin{tabular}{lcc}
\hline Mutation & Position & No. (\%) \\
\hline $\mathrm{G} \rightarrow \mathrm{C}$ & -617 & $25(64.1)$ \\
$\mathrm{A} \rightarrow \mathrm{G}$ & -604 & $20(51.3)$ \\
$\mathrm{G} \rightarrow \mathrm{C}$ and $\mathrm{A} \rightarrow \mathrm{G}$ & -617 and -604 & $25(64.1)$ \\
No mutation & & $14(35.9)$ \\
\hline
\end{tabular}
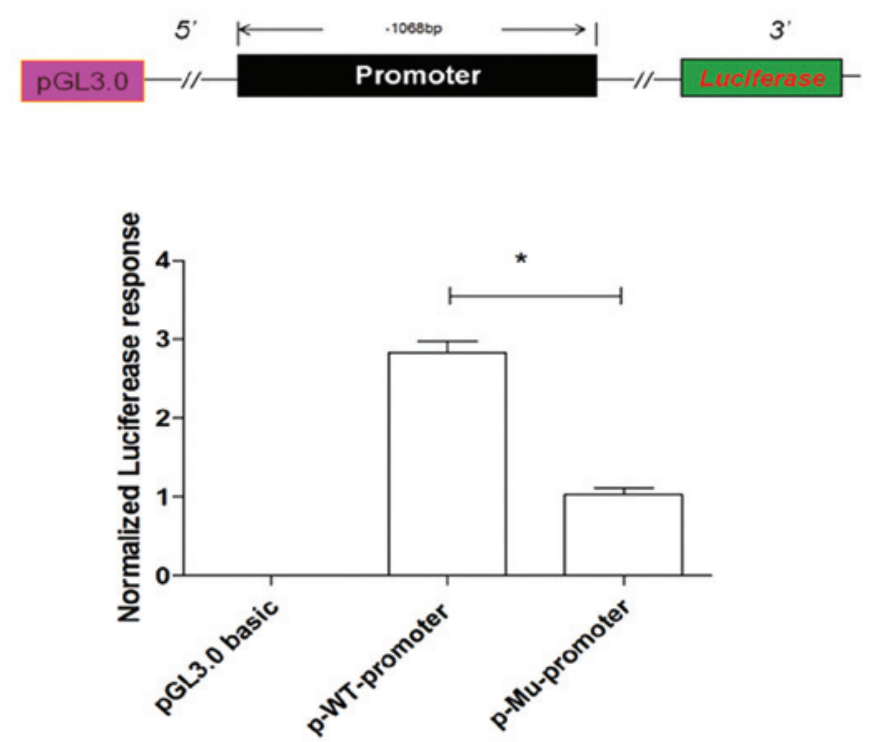

Figure 2. The mutation sites altered the activity of the microRNA-7 (miR-7) promoter. The 95D human lung cancer cells were transfected with plasmids cloned in a pGL3 basic vector containing the human miR-7 promoter [wild-type (WT), or mutation (Mu)] and the firefly luciferase reporter gene. The activities were normalized by a co-transfected pCMV-lacZ to correct for variations in transfection efficiencies. Representative data from one of three independent experiments is shown. ${ }^{*} \mathrm{P}<0.05$.

from lung cancer and normal lung tissues and subcloned into the pGL3-basic vector (referred to as the p-Mu promoter and the $\mathrm{p}$-WT promoter, respectively). The promoter activities were then evaluated by firefly luciferase reporter gene expression normalized to a co-transfected pCMV-lacZ as a control for transfection efficiency. The normalized luciferase reporter activities indicated that the mutations in the promoter significantly reduced promoter activity (Fig. 2, P <0.05). Compared with normal promoter activity, the mutated promoter activity decreased by $>50 \%$ in the pGL3 constructs. These data suggested that the mutation sites reduced the activity of the miR-7 promoter.

Promoter mutation reduces miR-7 expression in lung cancer cells. To further determine whether these mutations affected the activity of the miR-7 promoter, subsequently altering the expression of miR-7, the fragment containing the promoter region and the pre-miR-7 region $(-1068$ to +234$)$, with or without the two mutations, from lung cancer and normal lung tissues, was further amplified and subcloned into the pGL3-basic vector to construct miR-7 expression vectors 

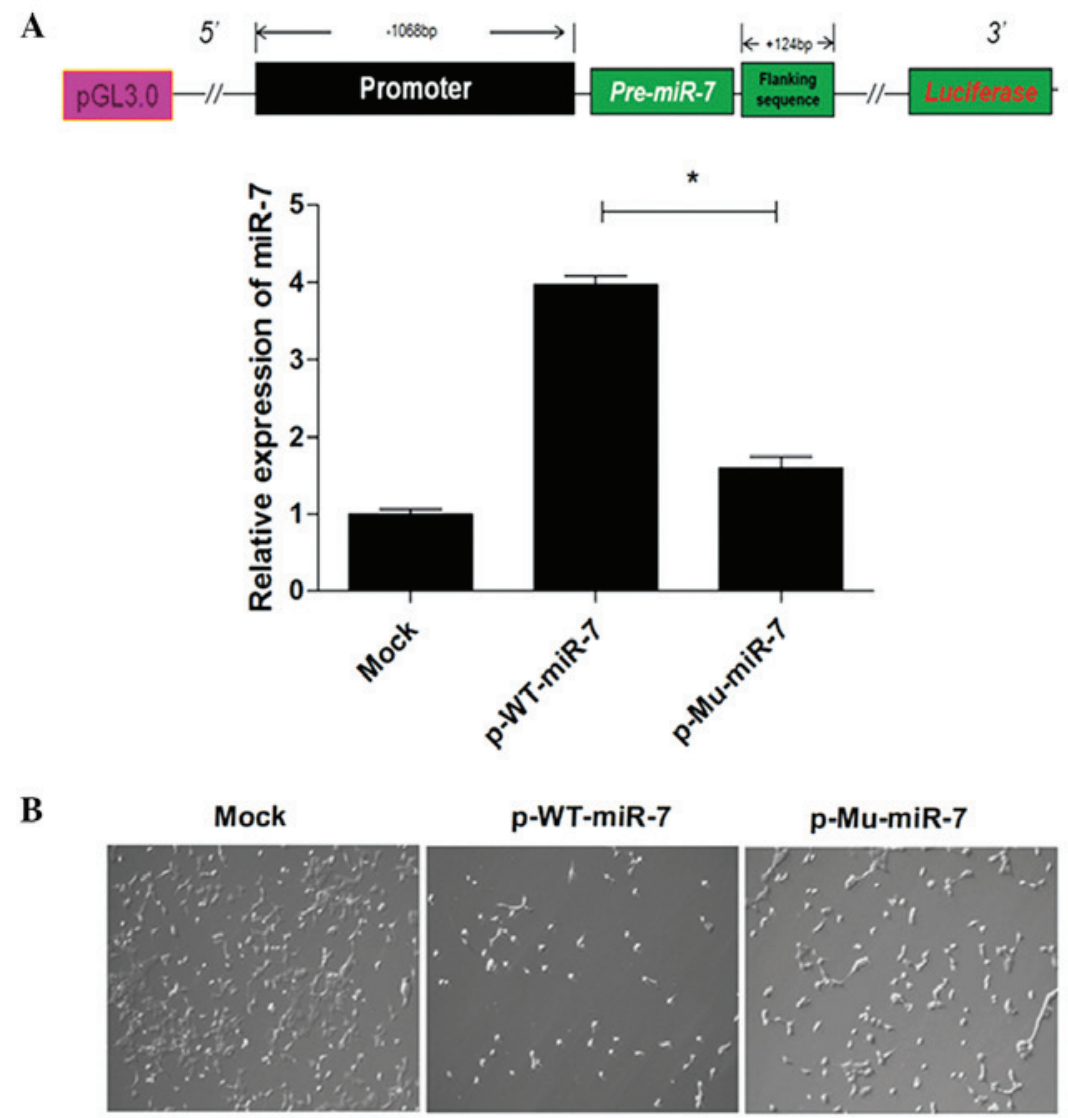

p-Mu-miR-7

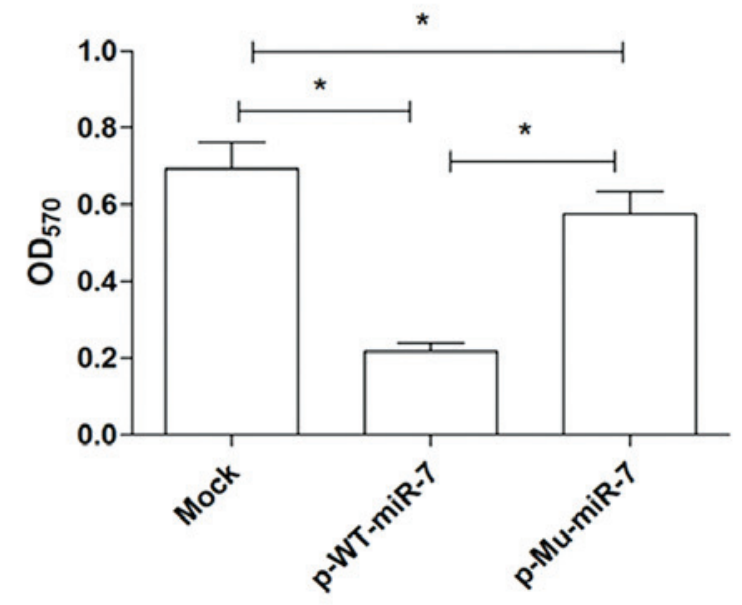

Figure 3. The mutation sites reduced the expression of microRNA-7 (miR-7) in lung cancer cells. (A) 95D cells were transfected with plasmids cloned in a pGL3 basic vector containing the human miR-7 promoter [wild-type (WT), or mutation (Mu)] and pre-miR-7. The relative expression of miR-7 was analyzed by quantitative polymerase chain reaction analysis. (B) The proliferation of 95D cells was also determined by the MTT assay. Magnification, x100. Representative data from one of three independent experiments is shown. " $\mathrm{P}<0.05$. OD, optical density.

(referred to as p-Mu-miR-7 and p-WT-miR-7, respectively). Human lung cancer cells were transiently transfected with these constructed plasmids. The relative expression level of miR-7 was then determined by qPCR analysis. The data revealed that the expression level of miR-7 was significantly decreased in the p-Mu-miR-7 vector transfection group compared with that in the p-WT-miR-7 vector transfection group (Fig. 3A, $\mathrm{P}<0.05$ ), indicating that the mutation sites reduced the expression of miR-7. Consistently, the growth of 95D cells in the p-Mu-miR-7 vector transfection group was higher compared with that in the p-WT-miR-7 vector transfec- tion group (Fig. 3B, $\mathrm{P}<0.05$ ), which was consistent with our previous findings (17). Combining these data demonstrated that the mutation sites significantly reduced the activity of the miR-7 promoter and altered the expression of miR-7, subsequently affecting its biological activity.

Promoter mutation is associated with repressed expression of miR-7 in lung cancer tissues. We next sought to determine whether the mutation of the miR-7 promoter was associated with the expression of miR-7 in lung cancer tissues. The relative expression of miR-7 was also assessed by qPCR in 
Table II. Association of miR-7 promoter mutations in cancer tissue with the clinicopathological characteristics of lung cancer patients $(n=39)$.

\begin{tabular}{|c|c|c|c|}
\hline \multirow{2}{*}{$\begin{array}{l}\text { Clinicopathological } \\
\text { characteristics }\end{array}$} & \multicolumn{2}{|c|}{$\begin{array}{c}\text { Promoter mutation status, } \\
\text { patient no. }(\%)\end{array}$} & \multirow[b]{2}{*}{ P-value } \\
\hline & Positive & Negative & \\
\hline Age, years & & & 0.396 \\
\hline$<60(\mathrm{n}=15)$ & $10(66.7)$ & $5(33.3)$ & \\
\hline$>60(n=24)$ & $15(62.5)$ & $9(37.5)$ & \\
\hline Gender & & & 0.635 \\
\hline Male $(n=33)$ & $21(63.6)$ & $12(36.4)$ & \\
\hline Female $(n=6)$ & $4(66.7)$ & $2(33.3)$ & \\
\hline Smoking status & & & 0.493 \\
\hline Ever $(n=32)$ & $21(65.6)$ & $11(34.4)$ & \\
\hline Never $(n=7)$ & $4(57.1)$ & $3(42.9)$ & \\
\hline Histologic types & & & 0.357 \\
\hline $\operatorname{SCC}(n=13)$ & $7(53.8)$ & $6(46.2)$ & \\
\hline $\operatorname{ADC}(n=17)$ & $13(76.5)$ & $4(23.3)$ & \\
\hline $\operatorname{LCC}(n=9)$ & $5(55.6)$ & $4(44.4)$ & \\
\hline Pathological stage & & & 0.020 \\
\hline $\mathrm{I}(\mathrm{n}=7)$ & $2(28.6)$ & $5(71.4)$ & \\
\hline II-IV (n=32) & $25(78.1)$ & $7(21.9)$ & \\
\hline
\end{tabular}

miR-7, microRNA-7; SCC, squamous cell carcinoma; ADC, adenocarcinoma; LCC, large-cell carcinoma.

39 lung cancer and 8 normal lung tissue specimens. Consistent with previous findings (14), the relative expression of miR-7 decreased significantly in lung cancer tissues compared with that in normal lung tissues (data not shown). Notably, we found that the expression level of miR-7 in lung cancer tissues with mutation sites was lower compared with that in lung cancer tissues without mutation sites (Fig. 4, P<0.05), indicating that the promoter mutation is closely associated with the repressed expression of miR-7 in lung cancer tissues.

Promoter mutation of miR-7 is associated with poor survival of lung cancer patients. Finally, the possible value of miR-7 promoter mutations in the prognosis of lung cancer patients was analyzed. There was no association between mutation and age at diagnosis, gender, or smoking status (Table II). miR-7 promoter mutations were more common in adenocarcinoma (ADC) $(13 / 17,76.5 \%)$ compared with squamous cell carcinoma $(7 / 13,53.8 \%)$ and large-cell carcinoma $(5 / 9,55.6 \%)$, although the difference was not statistically significant $(\mathrm{P}=0.357)$. However, a statistically significant association was observed between the mutations and stage II-IV disease according to the American Joint Committee on Cancer (AJCC), with miR-7 promoter mutations being present at a higher frequency in stage II-IV $(25 / 32,78.1 \%)$ compared with stage I disease (2/7, $40.0 \%)(\mathrm{P}=0.020)$. Finally, the Kaplan-Meier long-rank analysis revealed that the presence of promoter mutation of miR-7 was associated with poorer overall survival (Fig. 5, $\mathrm{P}=0.037$ ).

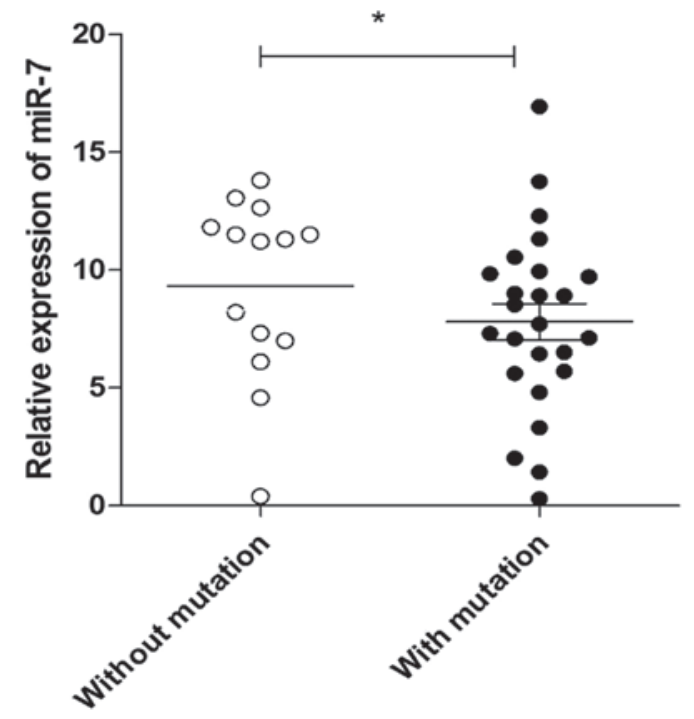

Figure 4. The mutation sites altered the expression of microRNA-7 (miR-7) in lung cancer cells. The relative expression of miR-7 in lung cancer tissues with mutation $(n=25)$ or without mutation $(n=14)$ was determined by quantitative polymerase chain reaction analysis. ${ }^{*} \mathrm{P}<0.05$.

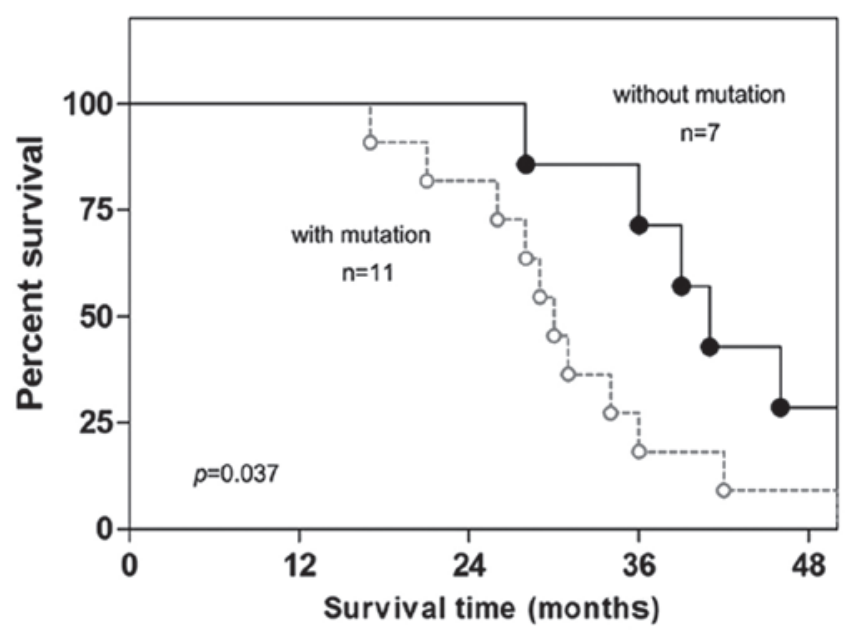

Figure 5. Promoter mutation of microRNA-7 (miR-7) was associated with poor survival of lung cancer patients. A total of 18 lung cancer patients were divided into two groups by promoter mutation of miR-7 (with mutation, $\mathrm{n}=11$; and without mutation, $n=7$ ). The overall survival rate was analyzed by the Kaplan-Meier method. The log-rank test was applied to compare survival between the groups.

\section{Discussion}

miR-7, a unique member of the miRNA family, has been proposed to be a new type of tumor suppressor gene, or oncomiRNA, in several tumor types $(13,18-20)$. In lung cancer, recent evidence demonstrated that the expression of miR-7 is decreased in cancer tissues (14). Moreover, miR-7 was found to inhibit the growth and metastasis of lung cancer cells and induce their apoptosis (21). Mechanistic evidence demonstrated that miR-7 was able to regulate the transduction of the Akt pathway, which is crucial for the growth and metastasis of tumor cells $(22,23)$. In line with these findings, our previous study also demonstrated that the overexpression of miR-7 inhibited the growth and metastasis of lung cancer cells (17). 
Consistently, more recent evidence further demonstrated that restoration of miR-7 expression suppressed the tumorigenicity of lung cancer cells in vivo (24) and overexpression of miR-7 improved the sensitivity of lung cancer cells to paclitaxel (25). These data suggested that miR-7 may be an important regulator and have multiple functions in the development of lung cancer. Of note, a recent study reported that stable overexpression of miR-7 promoted the growth and migration of a lung cancer cell clone by regulating the expression of Kruppel-like factor 4 (26). Combing these data indicated that the precise role of miR-7 in the development of lung cancer is complex, and closely associated with expression level, cellular context and growth conditions, as well as the specific targeted genes. Therefore, investigating the regulation of expression of miR-7 in cancers may be of significant value. However, to date, the mechanism underlying the altered expression of miR-7 remains largely unknown.

In the present study, we identified two mutation sites in the miR-7 promoter in lung cancer. Moreover, there was a positive association between the -617 and -604 sites. Importantly, the expression level of miR-7 in lung cancer with mutations of the promoter sites was clearly decreased. Moreover, the transcriptional activity driven by the mutated promoter from lung cancer tissues was significantly reduced. These results suggested that the reduced miR-7 expression in lung cancer is, at least in part, due to a defect in the promoter of the gene. In addition, mutations were not detected in all cancer tissues; in fact, no mutation was found in $\sim 35.9 \%$ of lung cancer patients. This finding suggests that other contributing factors are also involved in the altered expression of the miR-7 gene in lung cancer. Possible non-mutational causes for the reduced expression of miR-7 in lung cancer include the presence of transcription activators or repressors, as well as post-transcriptional factors. In fact, it was previously reported that c-Myc may bind to the promoter region of miR-7 and enhance miR-7 expression in lung cancer cells (13). Our recent findings further demonstrated that the human $\mathrm{R}$ antigen post-transcriptionally regulates the expression of miR-7 (17). In addition, recent evidence indicated that histone methylation or $\mathrm{CpG}$ methylation may affect the expression of distinct miRNA molecules in certain types of cancers $(27,28)$. Therefore, the predominant mechanism involved in the repressed expression of the miR-7 gene remains to be fully elucidated in future studies.

Accumulating data suggests that the mutation or methylation of the promoter region of certain molecules, which was found to be associated with major prognostic factors, has emerged as a useful novel biological marker for the prognosis of cancer patients. Similarly, miR-7 was reported to be downregulated in various cancers, including pancreatic and breast cancer, and was closely associated with the metastatic status of the patients $(12,29)$. In the present study, we observed that the frequency of miR-7 promoter mutation was higher in the ADC type of lung cancer, although the difference was not statistically significant. Moreover, miR-7 promoter mutations were also associated with stage II-IV of lung cancer. Finally, we further demonstrated a significant correlation between miR-7 promoter mutation and poor prognosis of lung cancer patients, indicating that miR-7 promoter mutation is of significant prognostic value. Similarly, it has been reported that miR-7 exhibits high diagnostic accuracy and may be a helpful adjunct to thyroid fine-needle aspiration biopsy (30). In addition, we also noted that there was no significant association between miR-7 promoter mutation and other factors, such as smoking status. Therefore, a Cox regression analysis including other prognostic factors, such as tumor size, lymph node status and adjuvant therapy, which were not investigated in the present study, may be of value for validation of the significance of promoter mutation of miR-7 in the prognosis of lung cancer patients.

In conclusion, the present study demonstrated that there are mutation sites in the miR-7 promoter region in lung cancer tissues, which alter the expression of miR-7. Moreover, the mutation sites of the miR-7 promoter are closely associated with the poor prognosis of lung cancer patients. These data may provide a novel insight in the mechanism underlying the altered expression of distinct miRNA molecules in lung cancer, and may be helpful in the development of novel prognostic methods and therapeutic targets against lung cancer.

\section{Acknowledgements}

This study was supported by the Program for New Century Excellent Talents in University, Ministry of Education of China (grant no. NCET-12-0661), the National Natural Science Foundation of China (grant nos. 31370918 and 81372347) and the International Cooperation Foundation of Guizhou Province (grant no. 2010-7031).

\section{References}

1. Osada $\mathrm{H}$ and Takahashi T: Genetic alterations of multiple tumor suppressors and oncogenes in the carcinogenesis and progression of lung cancer. Oncogene 21: 7421-7434, 2002.

2. Carneiro JG, Couto PG, Bastos-Rodrigues L, Bicalho MA, Vidigal PV, Vilhena A, Amaral NF, Bale AE, Friedman E and De Marco L: Spectrum of somatic EGFR, KRAS, BRAF, PTEN mutations and TTF-1 expression in Brazilian lung cancer patients. Genet Res (Camb) 96: e002, 2014.

3. Zöchbauer-Müller S, Fong KM, Virmani AK, Geradts J, Gazdar AF and Minna JD: Aberrant promoter methylation of multiple genes in non-small cell lung cancers. Cancer Res 61: 249-255, 2001.

4. Esteller M, Sanchez-Cespedes M, Rosell R, Sidransky D, Baylin SB and Herman JG: Detection of aberrant promoter hypermethylation of tumor suppressor genes in serum DNA from non-small cell lung cancer patients. Cancer Res 59: 67-70, 1999.

5. Kocaturk CI, Gunluoglu MZ, Cansever L, Demir A, Cinar U, Dincer SI and Bedirhan MA: Survival and prognostic factors in surgically resected synchronous multiple primary lung cancers. Eur J Cardiothorac Surg 39: 160-166, 2011.

6. Yanaihara N, Caplen N, Bowman E, Seike M, Kumamoto K, Yi M, Stephens RM, Okamoto A, Yokota J, Tanaka T, et al: Unique microRNA molecular profiles in lung cancer diagnosis and prognosis. Cancer Cell 9: 189-198, 2006.

7. Boeri M, Verri C, Conte D, Roz L, Modena P, Facchinetti F, Calabrò E, Croce CM, Pastorino U and Sozzi G: MicroRNA signatures in tissues and plasma predict development and prognosis of computed tomography detected lung cancer. Proc Natl Acad Sci USA 108: 3713-3718, 2011.

8. Huang CJ, Nguyen PN, Choo KB, Sugii S, Wee K, Cheong SK and Kamarul T: Frequent co-expression of miRNA-5p and $-3 p$ species and cross-targeting in induced pluripotent stem cells. Int J Med Sci 11: 824-833, 2014.

9. Hu Z, Chen X, Zhao Y, Tian T, Jin G, Shu Y, Chen Y, Xu L, Zen $\mathrm{K}$, Zhang C, et al: Serum microRNA signatures identified in a genome-wide serum microRNA expression profiling predict survival of non-small-cell lung cancer. J Clin Oncol 28: 1721-1726, 2010.

10. Xu K, Chen Z, Qin C and Song X: miR-7 inhibits colorectal cancer cell proliferation and induces apoptosis by targeting XRCC2. Onco Targets Ther 7: 325-332, 2014. 
11. Li Y, Li Y, Liu Y, Xie P, Li F and Li G: PAX6, a novel target of microRNA-7, promotes cellular proliferation and invasion in human colorectal cancer cells. Dig Dis Sci 59: 598-606, 2014.

12. Kong X,Li G, Yuan Y,He Y, Wu X,Zhang W, Wu Z, Chen T, Wu W, Lobie PE, et al: MicroRNA-7 inhibits epithelial-to-mesenchymal transition and metastasis of breast cancer cells via targeting FAK expression. PLoS One 7: e41523, 2012.

13. Chou YT, Lin HH, Lien YC, Wang YH, Hong CF, Kao YR, Lin SC, Chang YC, Lin SY, Chen SJ, et al: EGFR promotes lung tumorigenesis by activating miR-7 through a Ras/ERK/Myc pathway that targets the Ets2 transcriptional repressor ERF. Cancer Res 70: 8822-8831, 2010.

14. Xiong S, Zheng Y, Jiang P, Liu R, Liu X, Qian J, Gu J, Chang L, Ge D and Chu Y: PA28gamma emerges as a novel functional target of tumour suppressor microRNA-7 in non-small-cell lung cancer. Br J Cancer 110: 353-362, 2014.

15. Rai K, Takigawa N, Ito S, Kashihara H, Ichihara E, Yasuda T, Shimizu K, Tanimoto M and Kiura K: Liposomal delivery of MicroRNA-7-expressing plasmid overcomes epidermal growth factor receptor tyrosine kinase inhibitor-resistance in lung cancer cells. Mol Cancer Ther 10: 1720-1727, 2011.

16. Xu L, Wen Z, Zhou Y, Liu Z, Li Q, Fei G, Luo J and Ren T: microRNA-7-regulated TLR9 signaling-enhanced growth and metastatic potential of human lung cancer cells by altering the phosphoinositide-3-kinase, regulatory subunit 3/Akt pathway. Mol Biol Cell 24: 42-55, 2013.

17. Li YJ, Wang CH, Zhou Y, Liao ZY, Zhu SF, Hu Y, Chen C, Luo JM, Wen ZK and Xu L: TLR9 signaling repressed tumor suppressor miR-7 expression through up-regulation of HuR in human lung cancer cells. Cancer Cell Int 13: 90, 2013.

18. Yu Z, Ni L, Chen D, Zhang Q, Su Z, Wang Y, Yu W, Wu X, Ye J, Yang $\mathrm{S}$, et al: Identification of miR-7 as an oncogene in renal cell carcinoma. J Mol Histol 44: 669-677, 2013.

19. Zhang X, Hu S, Zhang X, Wang L, Zhang X, Yan B, Zhao J, Yang A and Zhang R: MicroRNA-7 arrests cell cycle in G1 phase by directly targeting CCNE1 in human hepatocellular carcinoma cells. Biochem Biophys Res Commun 443: 1078-1084, 2014.

20. Okuda H, Xing F, Pandey PR, Sharma S, Watabe M, Pai SK Mo YY, Iiizumi-Gairani M, Hirota S, Liu Y, et al: miR-7 suppresses brain metastasis of breast cancer stem-like cells by modulating KLF4. Cancer Res 73: 1434-1444, 2013.
21. Xiong S, Zheng Y, Jiang P, Liu R, Liu X and Chu Y: MicroRNA-7 inhibits the growth of human non-small cell lung cancer A549 cells through targeting BCL-2. Int J Biol Sci 7: 805-814, 2011.

22. Kefas B, Godlewski J, Comeau L, Li Y, Abounader R, Hawkinson M, Lee J, Fine H, Chiocca EA, Lawler S, et al: microRNA-7 inhibits the epidermal growth factor receptor and the Akt pathway and is down-regulated in glioblastoma. Cancer Res 68: 3566-3572, 2008.

23. Webster RJ, Giles KM, Price KJ, Zhang PM, Mattick JS and Leedman PJ: Regulation of epidermal growth factor receptor signaling in human cancer cells by microRNA-7. J Biol Chem 284: 5731-5741, 2009.

24. Li J, Zheng Y, Sun G and Xiong S: Restoration of miR-7 expression suppresses the growth of Lewis lung cancer cells by modulating epidermal growth factor receptor signaling. Oncol Rep 32: 2511-2516, 2014.

25. Liu R, Liu X, Zheng Y, Gu J, Xiong S, Jiang P, Jiang X, Huang E, Yang Y, Ge D, et al: MicroRNA-7 sensitizes non-small cell lung cancer cells to paclitaxel. Oncol Lett 8: 2193-2200, 2014.

26. Meza-Sosa KF, Pérez-García EI, Camacho-Concha N, López-Gutiérrez O, Pedraza-Alva G and Pérez-Martínez L: miR-7 promotes epithelial cell transformation by targeting the tumor suppressor KLF4. PLoS One 9: e103987, 2014.

27. Ben Gacem R, Ben Abdelkrim O, Ziadi S, Ben Dhiab M and Trimeche M: Methylation of miR-124a-1, miR-124a-2 and miR-124a-3 genes correlates with aggressive and advanced breast cancer disease. Tumour Biol 35: 4047-4056, 2014.

28. Fiaschetti G, Abela L, Nonoguchi N, Dubuc AM, Remke M, Boro A, Grunder E, Siler U, Ohgaki H, Taylor MD, et al: Epigenetic silencing of miRNA-9 is associated with HES1 oncogenic activity and poor prognosis of medulloblastoma. Br J Cancer 110: 636-647, 2014.

29. Singh S, Chitkara D, Kumar V, Behrman SW and Mahato RI: miRNA profiling in pancreatic cancer and restoration of chemosensitivity. Cancer Lett 334: 211-220, 2013.

30. Kitano M, Rahbari R, Patterson EE, Xiong Y, Prasad NB, Wang Y, Zeiger MA and Kebebew E: Expression profiling of difficult-to-diagnose thyroid histologic subtypes shows distinct expression profiles and identify candidate diagnostic microRNAs. Ann Surg Oncol 18: 3443-3452, 2011. 